E-mail: jzus@zju.edu.cn

\title{
Correspondence:
}

\section{Non-specific anti-viral approach towards Ebola virus infection: a comment on "Against Ebola: type I interferon guard risk and mesenchymal stromal cell combat sepsis"}

\author{
Beuy JOOB $^{1}$, Viroj WIWANITKIT ${ }^{\dagger \$ 2,3}$ \\ ( ${ }^{1}$ Sanitation 1 Medical Academic Center, Bangkok 10160, Thailand) \\ $\left({ }^{2}\right.$ Hainan Medical University, Haikou 571199, China) \\ $\left({ }^{3}\right.$ Dr. D.Y. Patil Medical University, Pune 411018, India) \\ †E-mail:wviroj@yahoo.com \\ doi:10.1631/jzus.B1500035
}

The recent "Viewpoint" by Zhang et al. (2015) entitled "Against Ebola: type I interferon guard risk and mesenchymal stromal cell combat sepsis", published in Journal of Zhejiang University-SCIENCE B (Biomedicine \& Biotechnology), is very interesting, which mentioned the possible role of non-specific anti-viral approach towards Ebola virus infection. They noted the role of interferon and "applying a non-specific anti-viral approach during the incubation period of virus infection as an essential protection to put the host's immune system into an alert state and henceforth to slow down the viral replication." In previous report, Zhang and Wang (2014) mentioned the long history of Ebola virus infection discovery. However, the success in disease management is still not reached. Indeed, the role of interferon in treatment of Ebola has been widely discussed (Shuchman, 2014). The effectiveness of interferon has been proved in some animal models (Smith et al., 2013).

However, in addition to interferon mentioned by Zhang et al. (2015), there have been other nonspecific anti-viral approaches for possible usefulness in the treatment of Ebola. The good examples include

\footnotetext{
Corresponding author

(D) ORCID: Viroj WIWANITKIT, http://orcid.org/0000-0003-1039-3728 (c) Zhejiang University and Springer-Verlag Berlin Heidelberg 2015
}

melatonin (Tan et al., 2014; Anderson et al., 2015) and antibodies, such as intravenous immunoglobulin (IVIG) (Rager-Zisman, 2014). Focusing on melatonin, Tan et al. (2014) first raised the possibility for its use as a new drug against Ebola. They noted that melatonin had activity targeting many pathological processes observed in Ebola virus infections (such as disseminated intravascular coagulation and multiple organ hemorrhage) and proposed that melatonin might have some advantages as a new treatment. Anderson et al. (2015) recently concluded that melatonin had roles in the reduction of pro-inflammatory cytokines and optimizing the appropriate immune response that could be useful for management of Ebola virus infection. Focusing on antibodies, immune sera are mentioned for effectiveness against the infection (Eickmann and Schumacher, 2014). However, the availability and safety of antibodies remain important points for further discussion (Rager-Zisman, 2014).

Nevertheless, there is still no clear evidence confirming the efficacy of interferon or other nonspecific anti-viral approaches towards Ebola. Further clinical trials are needed. Finally, we would also like to note that there are also some new reports on the possible effectiveness of specific antiviral drug towards Ebola. The latest report on the effectiveness of favipiravir against Ebola in animal models is one such potential new antiviral drug (Nagata et al., 2014; Oestereich et al., 2014; Mentré et al., 2015). Currently it is used for management of the infection in some settings (Mentré et al., 2015). However, the great concern is the lack of supporting evidence from scientific clinical trials (Nagata et al., 2014). 


\section{Compliance with ethics guidelines}

Beuy JOOB and Viroj WIWANITKIT declare that they have no conflict of interest.

\section{References}

Anderson, G., Maes, M., Markus, R.P., et al., 2015. Ebola virus: melatonin as a readily available treatment option. $J$. Med. Virol., 87(4):537-543. [doi:10.1002/jmv.24130]

Eickmann, M., Schumacher, B., 2014. Therapeutic use of immune sera. Ebola survivors as lifesavers? $M M W$ Fortschr. Med., 156(19):6 (in German). [doi:10.1007/ s15006-014-3606-5]

Mentré, F., Taburet, A.M., Guedj, J., et al., 2015. Dose regimen of favipiravir for Ebola virus disease. Lancet Infect. Dis., 15(2):150-151. [doi:10.1016/S1473-3099(14)71047-3]

Nagata, T., Lefor, A.K., Hasegawa, M., et al., 2014. Favipiravir: a new medication for the Ebola virus disease pandemic. Disaster Med. Public Health Prep., 29:1-3. [doi:10.1017/dmp.2014.151]

Oestereich, L., Lüdtke, A., Wurr, S., et al., 2014. Successful treatment of advanced Ebola virus infection with T-705 (favipiravir) in a small animal model. Antiviral Res., 105:17-21. [doi:10.1016/j.antiviral.2014.02.014]

Rager-Zisman, B., 2014. Antibody therapy to limit the spread of Ebola virus. Isr. Med. Assoc. J., 16(12):743.

Shuchman, M., 2014. Could interferon help treat Ebola? CMAJ, 186(16):1204. [doi:10.1503/cmaj.109-4906]

Smith, L.M., Hensley, L.E., Geisbert, T.W., et al., 2013. Interferon- $\beta$ therapy prolongs survival in rhesus macaque models of Ebola and Marburg hemorrhagic fever. J. Infect. Dis., 208(2):310-318. [doi:10.1093/infdis/jis921]

Tan, D.X., Korkmaz, A., Reiter, R.J., et al., 2014. Ebola virus disease: potential use of melatonin as a treatment. $J$. Pineal Res., 57(4):381-384. [doi:10.1111/jpi.12186]

Zhang, L., Wang, H., 2014. Forty years of the war against Ebola. J. Zhejiang Univ.-Sci. B (Biomed. \& Biotechnol.), 15(9):761-765. [doi:10.1631/jzus.B1400222]

Zhang, L., Wang, H., Zhang, Y.Q., 2015. Against Ebola: type I interferon guard risk and mesenchymal stromal cell combat sepsis. J. Zhejiang Univ.-Sci. B (Biomed. \& Biotechnol.), 16(1):1-9. [doi:10.1631/jzus.B1400365] 